\title{
Use of Extraction Chromatography in the Recycling of Critical Metals from Thin Film Leach Solutions
}

Nicolas Schaeffer, Sue M. Grimes*, Chris R. Cheeseman

Department of Civil and Environmental Engineering, Imperial College London, South Kensington Campus, London, United Kingdom, SW7 2AZ

*Corresponding author: s.grimes@imperial.ac.uk

Tel: +44 (0)207 5945966

\section{Keywords}

Extraction Chromatography; DODGAA-[C $\left.\mathrm{C}_{4} \operatorname{mim}\right]\left[\mathrm{Tf}_{2} \mathrm{~N}\right]-\mathrm{SIR}$; Critical Metals; Thin Film Leach Solutions;

\begin{abstract}
Phosphors and optoelectronic thin film electronic device layers contain critical metals including lanthanides and indium that should be recycled. Solvent impregnated resins (SIRs) containing (i) DEHPA (ii) DODGAA and (iii) DODGAA with the ionic liquid $\left[\mathrm{C}_{4} \mathrm{mim}\right]\left[\mathrm{Tf}_{2} \mathrm{~N}\right]$ are investigated in extraction chromatography methodologies to recover and separate critical metals from dilute solutions that model those leached from thin films. Optimum adsorption of metals occurs at $\mathrm{pH} 1.5-3.5$ but is highest on DODGAA-[C $\left.\mathrm{C}_{4} \operatorname{mim}\right]\left[\mathrm{Tf}_{2} \mathrm{~N}\right]$. The recovery and separation of adsorbed metal species on the DODGAA-[C $\left.\mathrm{C}_{4} \mathrm{mim}\right]\left[\mathrm{Tf}_{2} \mathrm{~N}\right] \mathrm{SIR}$ resin from solutions containing the glass matrix ions, $\mathrm{Ca}(\mathrm{II})$ and $\mathrm{Al}(\mathrm{III})$, along with $\mathrm{In}(\mathrm{III})$ and $\mathrm{Sn}(\mathrm{IV})$ or lanthanide ions is achieved by elution with $\mathrm{HNO}_{3} \cdot \mathrm{Ca}$ (II) and $\mathrm{Al}(\mathrm{III})$ are completely eluted with $0.1 \mathrm{M} \mathrm{HNO}_{3}$ retaining the target critical metal species on the resin. Separation of In from $\mathrm{Sn}$ is achieved by elution of $\mathrm{In}(\mathrm{III})$ with $2.5 \mathrm{M} \mathrm{HNO}_{3}$ and $\mathrm{Sn}(\mathrm{IV})$ with $5 \mathrm{M}$ acid. La is separated from the other lanthanides by elution of $\mathrm{La}(\mathrm{III})$ with $2.5 \mathrm{M} \mathrm{HNO}_{3}$ and the remaining lanthanides
\end{abstract}


with 5M acid. The SIR resins can be reused over a series of at least five cycles of loading, stripping, and rinsing to reduce reagent costs and achieve economic critical metal recovery by extraction chromatography.

\section{Introduction}

Electrical and electronic wastes include fractions such as phosphors and optoelectronic devices that consist of thin films containing rare earth elements and indium that are included in the European Union list of critical materials [1]. The demand for these elements for use in electronic applications is high and increasing and, because they are in short supply and there are limited opportunities for replacing them with substitutes, there is an urgent need to develop processes for their recovery. Although Waste Electrical and Electronic Equipment (WEEE) represents a potential source of these scarce elements, only $1 \%$ of the rare earth (RE) elements present in WEEE [2] for example, is currently recovered and recycled, and there are few significant reports on studies of recoveries from the dilute solutions that would arise from leaching of tin and indium from thin film electronic surfaces.

Thin films containing the rare earth (RE) elements and indium and tin are mainly oxide phases. Conventional industrial processing to separate RE elements from RE oxide sources, including ores, involves a combination of hydrometallurgy and solvent extraction $[3,4]$. Although the conventional method is favoured on the basis of being a simple process, with relatively low capital costs, recovery of the pure metals or metal oxides requires extraction and separation techniques, that: (i) use aggressive acid or alkali digestion, (ii) involve multi-stage separation procedures, (iii) produce large aqueous waste streams which require further treatment, and (iv) in the solvent extraction process, make use of solvents which are potentially flammable, volatile and toxic. Indium-tin oxide (ITO) thin films are optoelectronic materials with high 
conductivity, transparency to visible light and high reflectance in the infrared region and as such are extensively used as a transparent conducting layer in liquid crystal displays, plasma displays and solar cells $[5,6]$. ITO thin film coatings currently represent the largest end use for indium and are therefore a major potential source for recovery of this element [7]. The methods that have been considered for the recovery of indium from thin films have also involved the use of energy intensive pyrometallurgical methods [8], aggressive acid leaching [9], and solvent extraction $[9,10]$, some of which have included the use of techniques such as crosscurrent leaching [11] and extraction chromatography of indium, on silica gel impregnated with a high molecular weight carboxylic acid [12].

Extraction chromatography using solvent impregnated resins (SIRs) has generated a great deal of interest as an alternative to conventional separation processes. SIRs consist of organic extractants adsorbed onto a macro-porous polymeric matrix using a variety of methods [13]. This technique permits separations that combine the high selectivity of solvent extraction, the efficiency of chromatographic methods and the effectiveness of ion-exchange resins operating in dilute solutions. Task-specific SIRs can be synthesised by varying the polymeric support and/or the adsorbed extractant to achieve separation and recovery of a wide range of organic and inorganic compounds from various aqueous media [14]. The choice of extractant for taskspecific separations and recoveries in determining the extraction efficiency of any process is important. Suitable extractants, capable of extracting a range of metal ions, are chemically stable and have low aqueous solubility. Traditionally, organophosphorus extractants have been used extensively in extraction chromatography to separate rare earth elements [15-17] and the use of diglycolamides, particularly the neutral diglycolamide $\mathrm{N}, \mathrm{N}, \mathrm{N}^{\prime}, \mathrm{N}^{\prime}$-tetra(noctyl)diglycolamide (TODGA) to extract and separate actinide and lanthanide elements, has been reported, including their use in extraction chromatography [18-20]. 
Ionic liquids (ILs) are solvents usually consisting of organic cations and inorganic anions with melting points below $100{ }^{\circ} \mathrm{C}$ [21] that have received significant considerable attention as alternatives to conventional solvents. ILs have desirable properties (low melting point, low vapour pressure, density, viscosity, hydrophobicity, chemical and thermal stability etc.) that can be adjusted by varying either the anion or the cation to permit their use in a wide range of applications. In particular they have been used as solvents for the extraction, separation and purification of metals and metal oxides [21-23], including solubilising and separating trivalent RE oxides [24-30]. This includes the use of the ionic liquid 1-butyl-3-methylimidazolium bis(trifluoromethylsulfonyl)imide $\left[\mathrm{C}_{4} \mathrm{mim}\right]\left[\mathrm{Tf}_{2} \mathrm{~N}\right]$ in a liquid-liquid extraction process [30] for the recovery of RE elements from waste fluorescent lamp phosphor powders in which the RE elements were extracted with N,N-dioctyldiglycolamic acid (DODGAA) dissolved in the ionic liquid. Ionic liquids have also been used as extractants in SIR applications [31-34], for example in the separation of yttrium from other rare earths [31], and recovery of $\mathrm{Au}(\mathrm{III})$ [32], Pd(II) [33], and Bi(III) [34] from hydrochloric acid leach solutions.

We now report on the application of extraction chromatography using SIRs impregnated with (i) DODGAA, (ii) di-(2-ethylhexyl) phosphoric acid (DEHPA) and particularly (iii) for the first time, an extractant: ionic liquid system using a DODGAA:[C $\left.\mathrm{C}_{4} \mathrm{mim}\right]\left[\mathrm{Tf}_{2} \mathrm{~N}\right]$ mixture for the recovery and separation of rare earth elements, and of indium and tin ions from dilute solutions that model leach solutions obtained from treatment of thin films containing these ions.

\section{Experimental Section}

\subsection{Materials and Methods}

All chemicals were of reagent grade (Sigma-Aldrich) and, except for Amberlite XAD-7, were used without any further purification. Individual solutions of the elements studied were 
prepared by dissolving soluble salts of the metals (usually nitrate) in $1 \mathrm{~L}$ of deionized water. All batch sorption tests were performed in a temperature-controlled reciprocal shaker (Grant OLS 200, UK), and a digital pH meter (Fisherbrand Hydrus 500, USA) was used for pH measurements. Throughout the adsorption and elution experiments metal analyses were performed using inductively coupled plasma-optical emission spectroscopy (ICP-OES, with a Perkin Elmer Optima 7000 DV Spectrometer, USA). UV spectra were recorded using a UVVIS spectrophotometer (Shimadzu UV-2401 PC, Japan). High resolution characterisation of SIR surfaces was carried out on gold-coated samples using field emission gun scanning electron microscopy (FEGSEM) fitted with Oxford Instruments INCA energy dispersive (EDS) x-ray spectrometers (Gemini 1525, USA).

\subsection{Synthesis of the SIRs.}

Three SIRs based on Amberlite XAD-7, a hydrophilic macro-porous polyacrylic polymer with a pore volume of $0.5 \mathrm{~mL} \mathrm{~g}^{-1}$, particle size of $560-710 \mu \mathrm{m}$, pore size $0.03-0.04 \mu \mathrm{m}$ and surface area $380 \mathrm{~m}^{2} \cdot \mathrm{g}^{-1}$ were used in this work for the recovery of critical metals from thin film leach solutions. Prior to use the Amberlite XAD-7 was washed with a 1:1 ethanol:4M HCl solution for $2 \mathrm{~h}$ to remove any residual impurities and rinsed with distilled water to a neutral $\mathrm{pH}$ and dried at $50{ }^{\circ} \mathrm{C}$ for $24 \mathrm{~h}$. The solvents used to separately impregnate the resin were DEHPA, DODGAA and a DODGAA:ionic liquid $\left(\left[\mathrm{C}_{4} \mathrm{mim}\right]\left[\mathrm{Tf}_{2} \mathrm{~N}\right]\right)$ mixture. The SIRs were prepared by mixing $3.0 \mathrm{~g}$ of solvent (DEHPA, DODGAA or 1:1 DODGAA-[C $\left.\mathrm{C}_{4} \mathrm{mim}\right]\left[\mathrm{Tf}_{2} \mathrm{~N}\right]$ ) in $30 \mathrm{~mL}$ of acetone with $6.0 \mathrm{~g}$ Amberlite XAD-7, shaking the mixture overnight, and removing the acetone by rotary evaporation under vacuum at $40{ }^{\circ} \mathrm{C}$.

\subsection{SIR Selection - Resin characterisation and potential for metal adsorption}


The potential use of the three SIRs in the recovery and separation of critical metals from model thin film leach solutions was assessed in terms of the abilities of the SIRs to adsorb the metals from the solutions and to elute and separate them from the resins. For a specific metal ion $\left(\mathrm{M}^{\mathrm{n}+}\right)$, the amount adsorbed $\mathrm{q}\left(\mathrm{mg} \cdot \mathrm{g}^{-1}\right.$ of $\left.\mathrm{SIR}\right)$ onto the resin at any time $\mathrm{t}(\mathrm{min})$ is equal to:

$q_{t, M}=\frac{\left(C_{0}-C_{t}\right) V}{m}$

where $\mathrm{C}_{0}$ is the initial $\mathrm{M}^{\mathrm{n}+}$ solution concentration, $\mathrm{C}_{\mathrm{t}}$ is the residual concentration of $\mathrm{M}^{\mathrm{n}+}\left(\mathrm{mg} . \mathrm{L}^{-}\right.$ ${ }^{1}$ ) in the solution at time $\mathrm{t}, \mathrm{V}$ the solution volume (L) and $\mathrm{m}$ is the mass of SIR present $(\mathrm{g})$.

Resin Characterisation. The adsorption characteristics of the three SIR resins were established by $\mathrm{Y}$ (III) batch adsorption studies in which (i) $10 \mathrm{~mL}$ of $\mathrm{Y}$ (III) solutions of different concentrations $(50-1500 \mathrm{ppm})$ at $\mathrm{pH} 3.5$ were stirred separately with $0.25 \mathrm{~g}$ of each SIR for 60 minutes at $185 \mathrm{rpm}$ and $20{ }^{\circ} \mathrm{C}$, and, (ii) a $1000 \mathrm{ppm} \mathrm{Y(III)} \mathrm{solution} \mathrm{at} \mathrm{pH} 3.5$ was stirred with $0.25 \mathrm{~g}$ of each SIR over different time intervals of 0.75 to $60 \mathrm{~min}$. A pH value of 3.5 was selected to ensure that $\mathrm{pH}$ did not influence the adsorption of $\mathrm{Y}(\mathrm{III})$ because the adsorption of Y(III) decreases when $\mathrm{pH} \leq 1.5$. The residual metal content resulting from each batch adsorption experiment was obtained by collecting $2 \mathrm{~mL}$ aliquots of the solution for analysis by ICP-OES. In the case of the $1: 1$ DODGAA- $\left.\left[\mathrm{C}_{4} \operatorname{mim}\right]\left[\mathrm{Tf}_{2} \mathrm{~N}\right]\right)$ SIR, to ensure that neither the polymeric support nor the IL had a direct influence on the metal adsorption, similar characterisation studies were carried out on both Amberlite XAD-7 and a 1:1 (w/w) Amberlite XAD-7:[C 4 mim $]\left[\mathrm{Tf}_{2} \mathrm{~N}\right]$ mixture in the absence of the extractant phase. No significant $\mathrm{Y}(\mathrm{III})$ adsorption occurred on either of these resin phases in the absence of the extractant.

The results are expressed as (i) the quantity of Y(III) adsorbed, $\mathrm{q}_{\mathrm{e}}\left(\mathrm{mg} \cdot \mathrm{g}^{-1}\right.$ of SIR) for different initial concentrations of $\mathrm{Y}(\mathrm{III})\left(\mathrm{C}_{0}\right.$ in $\left.\mathrm{ppm}\right)$, (Figure 1) and, as (ii) the quantity of $\mathrm{Y}(\mathrm{III})$ adsorbed, $\mathrm{q}_{\mathrm{t}}$ (mg. $\mathrm{g}^{-1}$ of SIR), for different contact times (Figure 2). 


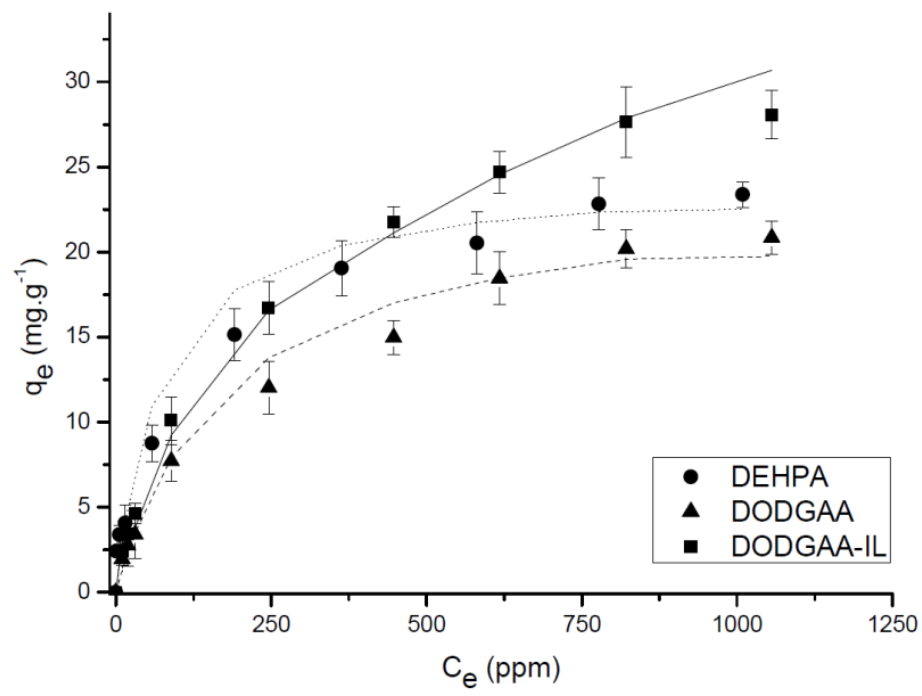

Figure 1. The adsorption isotherm for Y(III) adsorption onto DEHPA, DODGAA and DODGAA-IL containing SIRs.

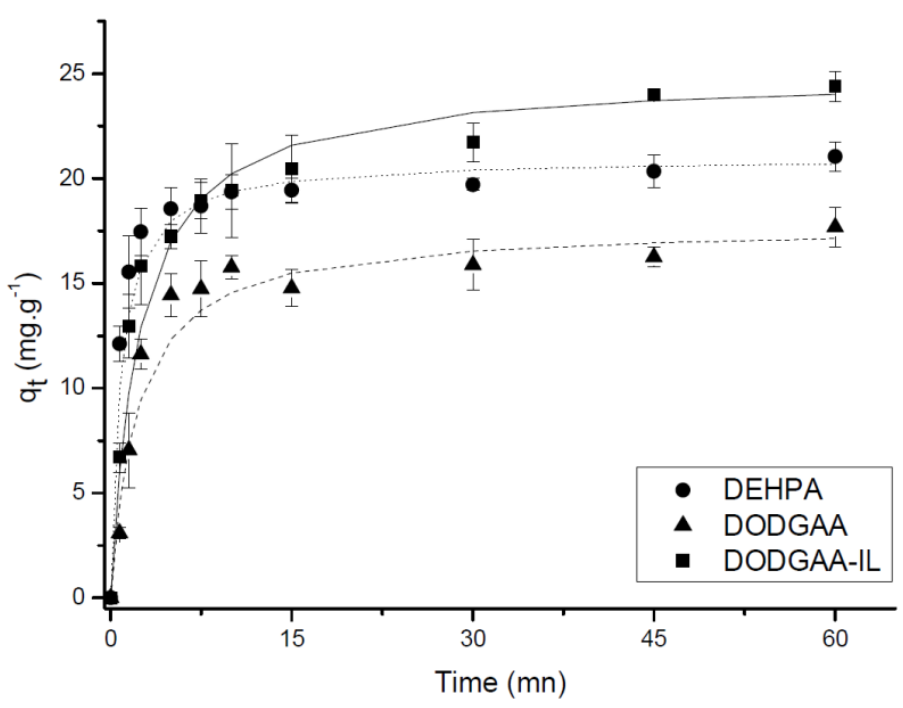

Figure 2. The pseudo-second order adsorption kinetics for Y(III) adsorption onto DEHPA, DODGAA and DODGAA-IL containing SIRs.

Adsorption and Separation of Metals as a Function of $p H$. Studies on the adsorption of metals from $500 \mathrm{ppm}$ single element solutions at different $\mathrm{pH}$ values $(0.2-4.0)$ on the three SIRs were carried out under the same standard test conditions as those described above. The metal solutions used to model thin film leach solutions were of three types: (a) lanthanide ion (La(III), $\mathrm{Eu}(\mathrm{III}), \mathrm{Gd}(\mathrm{III})$ and $\mathrm{Y}(\mathrm{III})$ ) solutions, (b) tin and indium solutions, and (c) calcium and aluminium solutions. Information was obtained on the adsorption of $\mathrm{Ca}$ (II) and $\mathrm{Al}$ (III) as the 
most likely ions that could be leached from glass substrates along with the critical metals of interest. The results are expressed for the three SIRs in Figure 3 as percentage adsorption as a function of $\mathrm{pH}$.
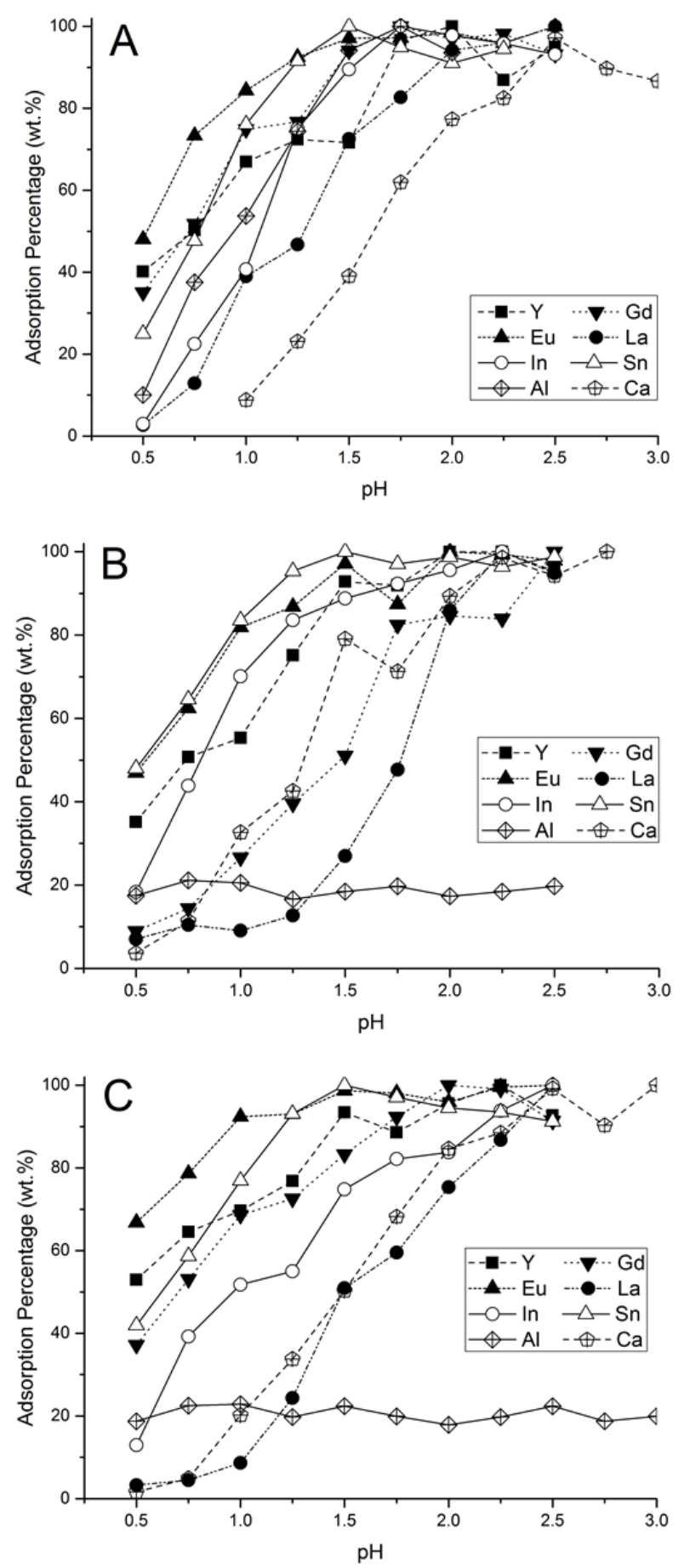

Figure 3. Average percentage adsorption as a function of $\mathrm{pH}$ for the study elements onto (A) DEHPA, (B) DODGAA and (C) DODGAA-IL SIRs 


\subsection{Elution and separation of critical metals from thin film leach solutions adsorbed on the DODGAA-[C4mim][Tf 2 N] SIR}

Model multi-element solutions containing $1000 \mathrm{ppm}$ of the single elements used in this study for adsorption and elution experiments were prepared in nitric acid media for the production of simulated leach solutions containing: (i) $\mathrm{Sn}(\mathrm{IV})$ and $\mathrm{In}(\mathrm{III})$, (ii) glass matrix components such as $\mathrm{Ca}(\mathrm{II})$ and $\mathrm{Al}(\mathrm{III})$ and (iii) the rare earth elements $\mathrm{La}(\mathrm{III}), \mathrm{Eu}(\mathrm{III}), \mathrm{Gd}(\mathrm{III})$ and $\mathrm{Y}(\mathrm{III})$. Separation tests were carried out using an ion-exchange column with an inner diameter of 15 $\mathrm{mm}$ and height of $260 \mathrm{~mm}$ packed with the DODGAA-IL impregnated resin. Prior to separation, the DODGAA-IL SIR was loaded with 1000 ppm multi-element solutions at pH 3.5. Elution was achieved by passing $\mathrm{HNO}_{3}$ solutions of gradually increasing molarity $(0.1 \mathrm{M}$ to $5.0 \mathrm{M}$ ) through the column at a flow rate of $1.5 \mathrm{~mL} \cdot \mathrm{min}^{-1}$. The effluent at the column outlet was collected in $5 \mathrm{~mL}$ portions and analysed by ICP-OES for metal content. The results of the elution studies are shown as cumulative elution concentrations in Figure 4 for $\mathrm{Sn}$ (IV), In(III), $\mathrm{Ca}(\mathrm{II})$ and $\mathrm{Al}(\mathrm{III})$, and in Figure 5 for the lanthanides, $\mathrm{Ca}(\mathrm{II})$ and $\mathrm{Al}(\mathrm{III})$.

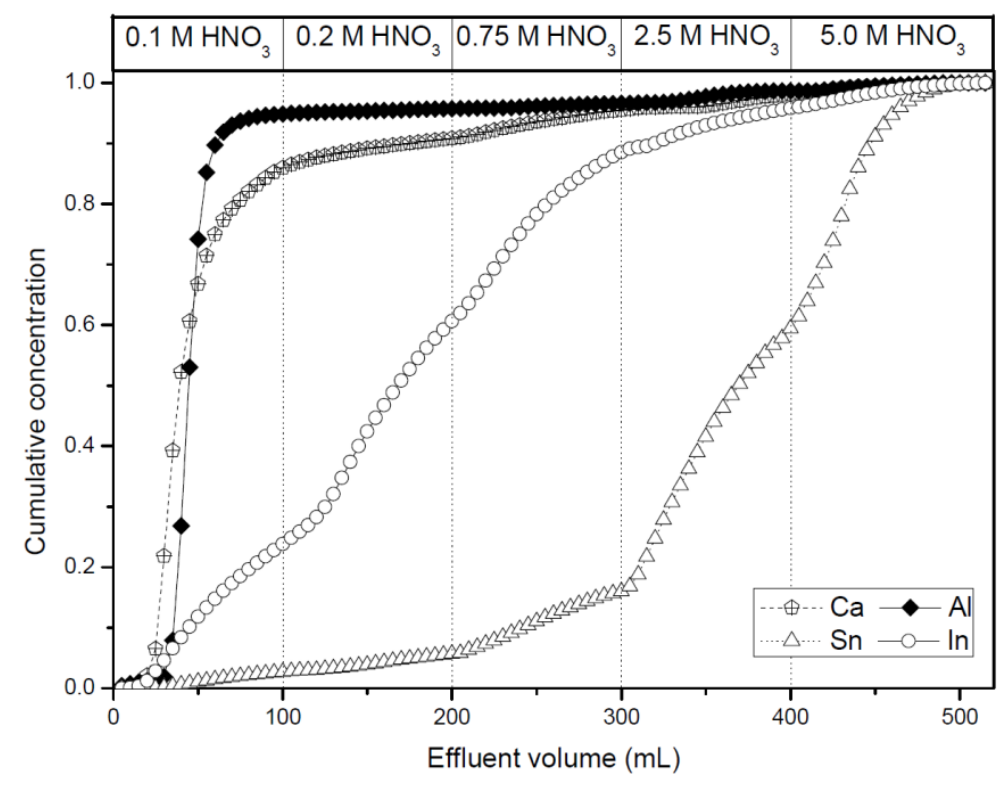

Figure 4. Chromatogram of $\mathrm{Sn}(\mathrm{IV}), \mathrm{In}(\mathrm{III}), \mathrm{Al}(\mathrm{III})$ and $\mathrm{Ca}(\mathrm{II})$ with gradient elution using DODGAA-IL-impregnated resin as stationary phase. 


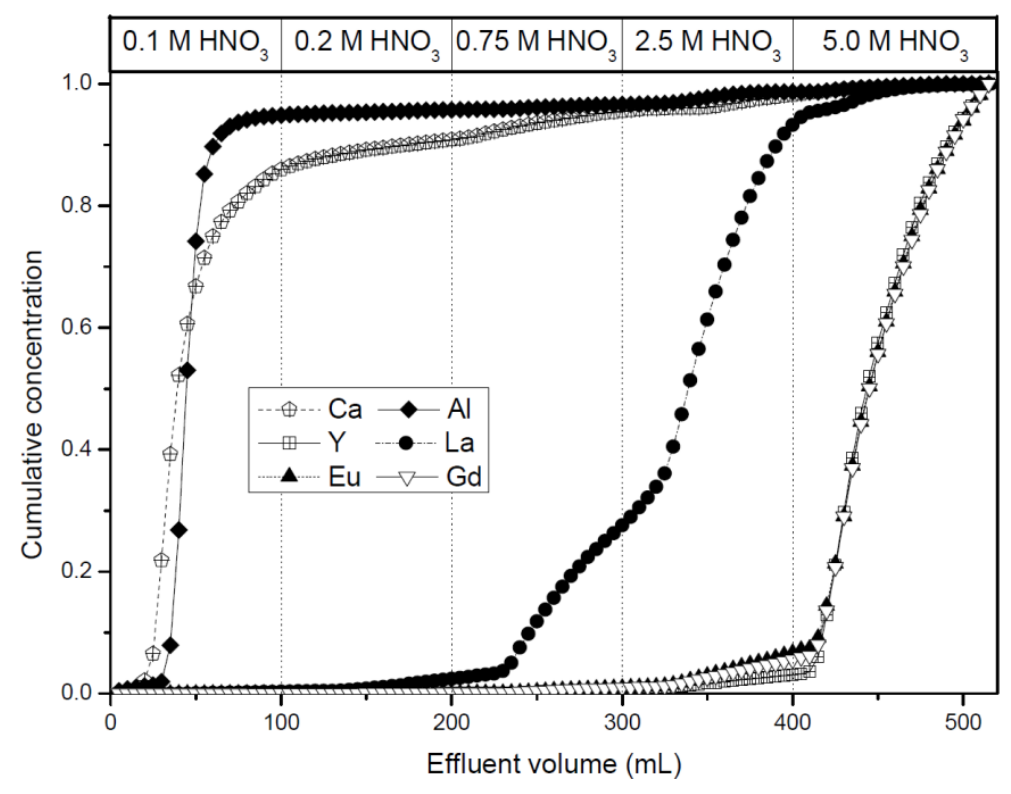

Figure 5. Chromatogram of $\mathrm{REE}(\mathrm{III}), \mathrm{Al}(\mathrm{III})$ and $\mathrm{Ca}(\mathrm{II})$ with gradient elution using DODGAAIL-impregnated resin as stationary phase.

\subsection{Recycling of SIRs}

Five cycles of SIR loading with Y(III), stripping and rinsing were performed in order to quantify potential extractant and IL losses. For the DEHPA and DODGAA impregnated SIRs the loss of extractant was determined by titration of a $5 \mathrm{~mL}$ aliquot with a $50-50 \mathrm{vol} . \% \mathrm{NaOH}-$ ethanol solution and confirmed by recording the mass change of the SIR, dried after each cycle. For DODGAA-IL SIRs, a small sample $(0.200 \mathrm{~g})$ was taken at the end of the cycle and shaken overnight in $10 \mathrm{~mL}$ ethanol. The DODGAA concentration inside the resin was determined by titration of a $5 \mathrm{~mL}$ aliquot with a $50-50$ vol. $\% \mathrm{NaOH}$-ethanol solution. The concentration of $\left[\mathrm{C}_{4} \mathrm{mim}\right]^{+}$ions was determined by UV-VIS spectrophotometry at wavelength $211 \mathrm{~nm}$ [35]. The results are shown in Figure 6 for each SIR. 

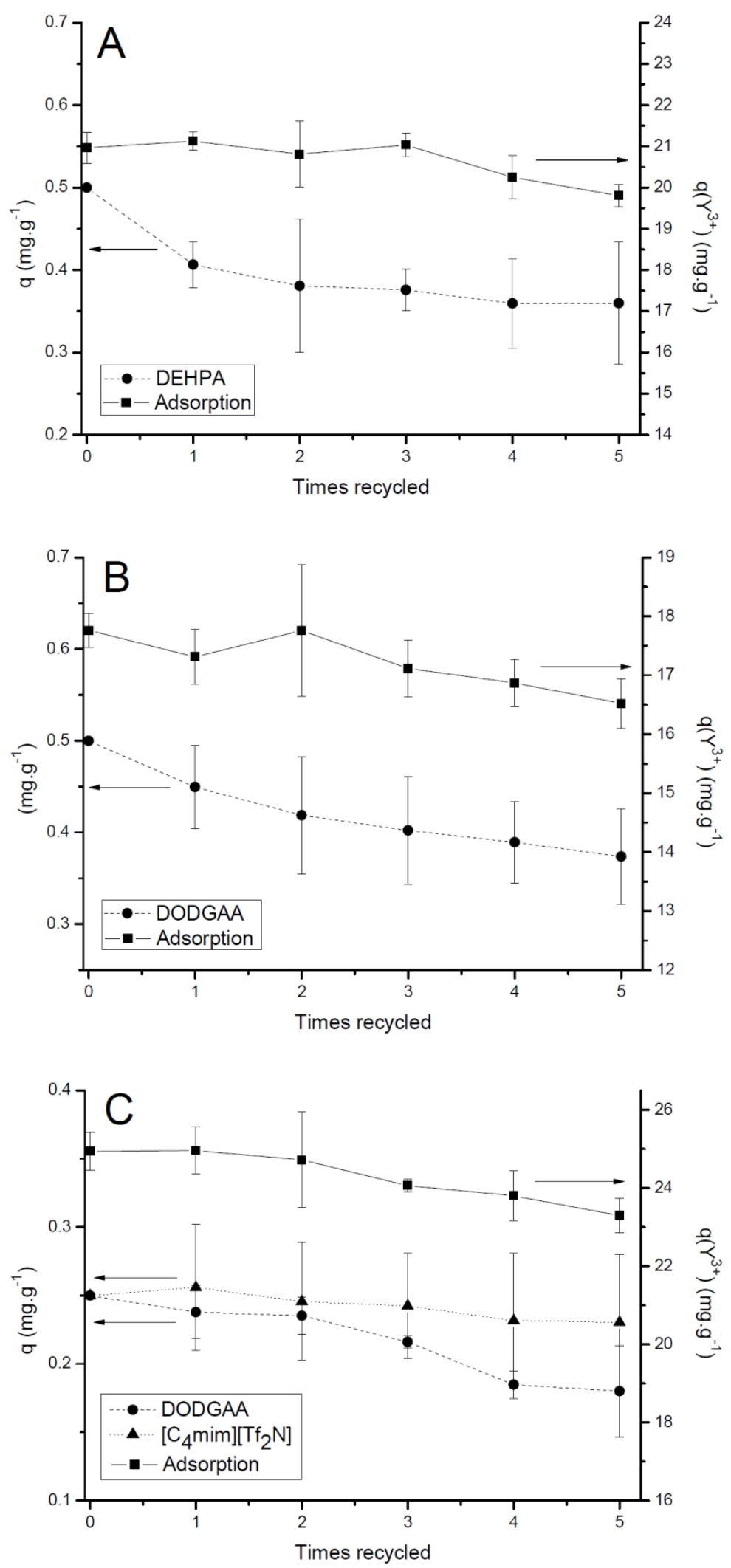

Figure 6. Extractant and IL loading, and $\mathrm{Y}^{3+}$ adsorption capacity as a function of times recycled for A) DEHPA, B) DODGAA and C) DODGAA-IL containing SIRs. 


\section{Results and Discussion}

\subsection{Resin selection}

The results of the resin characterisation studies using Y(III) model solutions presented in Figures 1 and 2 show that all three SIRs are good adsorbents for this ion. In all cases, the initial sorption capacity of Y(III) increases almost linearly with an increase in the solution concentration until the concentrations are greater than $750 \mathrm{ppm}$ and the resins become saturated. The Langmuir and Freundlich isotherm parameters for adsorption of Y(III), calculated for all three SIRs from the data used for the evaluation of the SIRs obtained by linear regression, are presented in Table 1. For the Langmuir isotherms, the value of the equilibrium parameter $\mathrm{R}_{\mathrm{L}}$, where $\mathrm{R}_{\mathrm{L}}$ is $1 /\left(1+b \mathrm{C}_{\mathrm{o}}\right)$, indicates that adsorption falls in the favourable range for all three systems. Although adsorption is favourable for all three SIRs, the higher adsorption capacity for the DODGAA-IL SIR, shown in Figures 1 and 2, and the significantly higher maximum adsorption capacity $\left(28.7 \mathrm{mg} \mathrm{Y.g}^{-1}\right)$ from Table 1 confirm the DODGAA-IL system should be the SIR of choice.

Table 1 Langmuir and Freundlich parameter for Y(III) adsorption onto DEHPA, DODGAA and DODGAA-IL containing resins.

\begin{tabular}{lccccccc}
\hline & \multicolumn{3}{c}{ Langmuir Isotherm } & \multicolumn{3}{c}{ Freundlich Isotherm } \\
\cline { 2 - 8 } & $\mathrm{q}_{\max }$ & $\mathrm{b}$ & $\mathrm{R}_{\mathrm{L}}$ & $\mathrm{r}^{2}$ & $\mathrm{~K}_{\mathrm{f}}$ & $\mathrm{n}$ & $\mathrm{r}^{2}$ \\
\hline DEHPA & 24.4 & 0.014 & 0.99 & 0.066 & 0.91 & 2.96 & 0.936 \\
DODGAA & 23.9 & 0.0055 & 0.99 & 0.15 & 0.61 & 1.9 & 0.98 \\
DODGAA-IL & 28.7 & 0.022 & 0.98 & 0.043 & 2.88 & 2.86 & 0.99 \\
\hline
\end{tabular}

Changes to the surface of the DODGAA-IL SIR following adsorption of Y(III) are illustrated in the FEGSEM images in Figure 7 that show the formation of a surface adsorbed Y(III)containing phase identified in the EDS spectrum that is not present in the SIR before treatment with the Y(III) solution. The EDS spectrum also shows the presence of the elements of sulfur 
and fluorine in the surface phase, suggesting that the $\left[\mathrm{Tf}_{2} \mathrm{~N}\right]^{-}$anion in the $\mathrm{IL}$ plays a role in the extraction of Y(III) from solution onto the DODGAA-IL SIR.

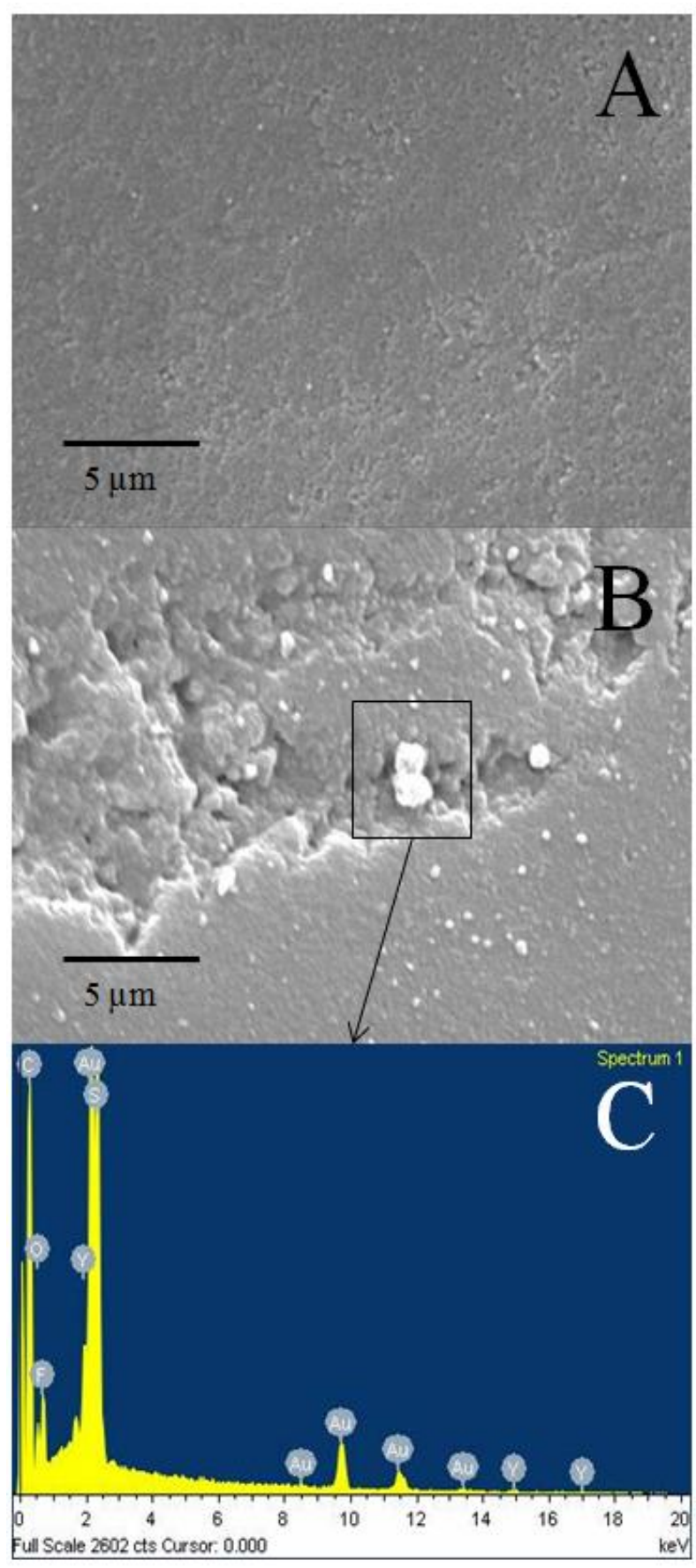

Figure 7. FEGSEM images showing the changes to the surface of the DODGAA-IL SIR following adsorption of Y(III) 


\subsection{Effect of pH on adsorption of metal ions on DEHPA, DODGAA and DODGAA-}

\section{IL SIRs}

The effects of $\mathrm{pH}$ on the absorption of target metals from aqueous leach solutions of thin films were studied for (a) the lanthanide elements La(III), Eu(III), Gd(III) and Y(III); (b) Sn(IV) and $\mathrm{In}(\mathrm{III})$; and (c) the glass matrix elements $\mathrm{Ca}(\mathrm{II})$ and $\mathrm{Al}(\mathrm{III})$, on DEPHA, DODGAA, and DODGAA-IL SIRs. The percentage absorption data in Figure 3A show an increase in adsorption, from lower values at $\mathrm{pH} 0.5$, reaching approximately $100 \%$ for all metal ions on the DEPHA SIR, while the data in Figures 3B and 3C for adsorption onto the DODGAA and DODGAA-IL SIRs show, for all metal ions except for $\mathrm{Al}(\mathrm{III})$, an increase in adsorption from lower values at $\mathrm{pH} 0.5$ to approximately $100 \%$ at $\mathrm{pH} 2.0$ to 3.0. Lower extraction of $\mathrm{Al}(\mathrm{III})$ on these two SIRs is an advantage because a partial separation of this glass matrix element from the target elements is achieved even on adsorption. The order of extraction of the metal species studied on each $\mathrm{SIR}$ is: $\mathrm{Eu}(\mathrm{III}) \geq \mathrm{Gd}(\mathrm{III}) \approx \mathrm{Sn}(\mathrm{IV})>\mathrm{Y}(\mathrm{III}) \geq \mathrm{In}(\mathrm{III}) \approx \mathrm{Al}(\mathrm{III}) \geq \mathrm{La}(\mathrm{III})>\mathrm{Ca}(\mathrm{II})$ (for DEPHA); $\mathrm{Eu}(\mathrm{III}) \approx \mathrm{Sn}(\mathrm{IV}) \geq \mathrm{Y}(\mathrm{III}) \approx \mathrm{In}(\mathrm{III})>\mathrm{Gd}(\mathrm{III}) \approx \mathrm{Ca}(\mathrm{II}) \geq \mathrm{La}(\mathrm{III})>>\mathrm{Al}(\mathrm{III})$ (for DODGAA); and, $\mathrm{Eu}(\mathrm{III}) \geq \mathrm{Sn}(\mathrm{IV}) \geq \mathrm{Y}(\mathrm{III}) \approx \mathrm{Gd}(\mathrm{III})>\mathrm{In}(\mathrm{III})>\mathrm{La}(\mathrm{III}) \approx \mathrm{Ca}(\mathrm{II})>>\mathrm{Al}(\mathrm{III})$ (for DODGAA-IL). These results, taken with the higher adsorption capacity data for the DODGAA-IL SIR shown in Figures 1 and 2, have led to the selection of this SIR saturated with the target metals at $\mathrm{pH} 3.5$ in subsequent elution and separation studies.

\subsection{Elution and separation of critical metals from thin film leach solutions adsorbed onto the DODGAA-[ $\left.\mathrm{C}_{4} \mathrm{mim}\right]\left[\mathrm{Tf}_{2} \mathrm{~N}\right] \mathrm{SIR}$}

The results of using nitric acid solutions of increasing acid concentration to elute metal ions from a DODGAA- $\left[\mathrm{C}_{4} \mathrm{mim}\right]\left[\mathrm{Tf}_{2} \mathrm{~N}\right] \mathrm{SIR}$ chromatographic column saturated with metal ions at pH 3.5 from model thin film leach solutions containing (i) $\operatorname{Sn}(\mathrm{IV})$ and $\mathrm{In}(\mathrm{III})$, (ii) the glass matrix components $\mathrm{Ca}(\mathrm{II})$ and $\mathrm{Al}(\mathrm{III})$ and (iii) $\mathrm{La}(\mathrm{III}), \mathrm{Eu}(\mathrm{III}), \mathrm{Gd}(\mathrm{III})$ and $\mathrm{Y}(\mathrm{III})$ are illustrated 
in Figures 4 and 5 respectively which show the cumulative metal concentrations in the eluent with increasing eluent acid strength. The target elements (Sn(IV) and $\operatorname{In}(\mathrm{III})$ ) and the lanthanides are readily separated from the glass matrix elements $\mathrm{Ca}(\mathrm{II})$ and $\mathrm{Al}(\mathrm{III})$ which are completely eluted from the column with $0.1 \mathrm{M} \mathrm{HNO}_{3}$ while all of the target elements are retained on the column with this eluent. The data in Figure 4 show that it is also possible to separate $\mathrm{Sn}(\mathrm{IV})$ from In(III) which is fully eluted from the column with nitric acid solutions of concentrations less than $2.5 \mathrm{M}$. For the rare earth elements adsorbed on the DODGAA$\left[\mathrm{C}_{4} \mathrm{mim}\right]\left[\mathrm{Tf}_{2} \mathrm{~N}\right] \mathrm{SIR}$ column, a further separation (Figure 5) of $\mathrm{La}(\mathrm{III})$ from the other lanthanide ions present can be achieved using $2.5 \mathrm{M} \mathrm{HNO}_{3}$ because the other lanthanide ions are eluted only in more concentrated acid solutions.

\subsection{Regeneration and Reuse of the SIRs columns}

All three SIR columns DEHPA, DODGAA and DODGAA- $\left[\mathrm{C}_{4} \operatorname{mim}\right]\left[\mathrm{Tf}_{2} \mathrm{~N}\right]$ can be regenerated at the end of any elution stage by rinsing with $5.0 \mathrm{M} \mathrm{HNO}_{3}$. A series of five cycles of loading with Y(III), stripping, and rinsing were carried out on the SIR systems to check on potential loss of extractant from all three SIRs and of the IL from DODGAA-[C $\left.\mathrm{C}_{4} \operatorname{mim}\right]\left[\mathrm{Tf}_{2} \mathrm{~N}\right] \mathrm{SIR}$. The results (Figure 6) show that Y(III) adsorption drops only slightly $(<6 \%)$ from the initial loading value on all three SIRs even after five reuse cycles. For the DEPHA and DODGAA SIRs extractant losses of about $20 \%$ are found after one or two reuse cycles but these are followed by three further cycles in which very little further extractant losses occur. Almost no IL losses occur from the DODGAA- $\left[\mathrm{C}_{4} \mathrm{mim}\right]\left[\mathrm{Tf}_{2} \mathrm{~N}\right] \mathrm{SIR}$, even after 5 cycles and, although there is a significant loss of DODGAA between the second and fourth reuse cycles, this has not had an effect on the ability of the DODGAA-[C $\left.\mathrm{C}_{4} \operatorname{mim}\right]\left[\mathrm{Tf}_{2} \mathrm{~N}\right]$ SIR to adsorb and elute Y(III). The ability to regenerate and reuse the SIRs in the recovery of critical metals from thin film leach 
solutions is important in reducing reagent costs and improving the economics of any process based on this methodology.

\section{Conclusions}

Many thin films used in electronic devices including fluorescent tube phosphors and optoelectronic conducting layers contain elements such as the lanthanides and indium that are regarded as critical materials that should be recovered for re-use and recycle. Leaching of the thin films to solubilise the critical metals usually results in dilute solutions from which the elements have to be concentrated to permit recovery. Three SIR resins, impregnated with (i) DEHPA, (ii) DODGAA and (iii) DODGAA and the ionic liquid $\left[\mathrm{C}_{4} \mathrm{mim}\right]\left[\mathrm{Tf}_{2} \mathrm{~N}\right]$, were used to assess the potential of extraction chromatography in the recovery and separation of rare earth elements, and of indium and tin from solutions that model those obtained from treatment of thin films containing rare earth elements or indium and tin. Resin characterisation studies using Y(III) solutions showed that good adsorption occurred on all three SIR resins. The maximum adsorption capacity was highest for the DODGAA-[C $\left.\mathrm{C}_{4} \operatorname{mim}\right]\left[\mathrm{Tf}_{2} \mathrm{~N}\right]$ resin for which an EDS spectrum of the Y(III)-loaded surface showed that the IL as well as DODGAA played a role in the extraction of the lanthanide ion from solution. The adsorption of the lanthanides, $\mathrm{In}(\mathrm{III}), \mathrm{Sn}(\mathrm{IV})$ and the potentially contaminating glass matrix ions, $\mathrm{Ca}(\mathrm{II})$ and $\mathrm{Al}(\mathrm{III})$, is low and incomplete from single element metal solutions at $\mathrm{pH} 0.5$ but increases for all ions except $\mathrm{Al}(\mathrm{III})$ on the DODGAA-[C $4 \mathrm{mim}]\left[\mathrm{Tf}_{2} \mathrm{~N}\right]$ and DODGAA SIRs to give almost complete adsorption in the $\mathrm{pH}$ range $1.5-3.5$. The order of adsorption of the metal species studied is: $\mathrm{Eu}(\mathrm{III}) \geq \mathrm{Gd}(\mathrm{III}) \approx \mathrm{Sn}(\mathrm{IV})>\mathrm{Y}(\mathrm{III}) \geq \mathrm{In}(\mathrm{III}) \approx \mathrm{Al}(\mathrm{III}) \geq \mathrm{La}(\mathrm{III})>\mathrm{Ca}(\mathrm{II})$ (for DEPHA) $\mathrm{Eu}(\mathrm{III}) \approx$ $\mathrm{Sn}(\mathrm{IV}) \geq \mathrm{Y}(\mathrm{III}) \approx \mathrm{In}(\mathrm{III})>\mathrm{Gd}(\mathrm{III}) \approx \mathrm{Ca}(\mathrm{II}) \geq \mathrm{La}(\mathrm{III})>>\mathrm{Al}(\mathrm{III})$ (for DODGAA); and, $\mathrm{Eu}(\mathrm{III}) \geq$ $\mathrm{Sn}(\mathrm{IV}) \geq \mathrm{Y}(\mathrm{III}) \approx \mathrm{Gd}(\mathrm{III})>\mathrm{In}(\mathrm{III})>\mathrm{La}(\mathrm{III}) \approx \mathrm{Ca}(\mathrm{II})>>\mathrm{Al}(\mathrm{III})$ (for DODGAA-IL). 
The recovery and separation of adsorbed metal species from DODGAA-[C $\left.\mathrm{C}_{4} \mathrm{mim}\right]\left[\mathrm{Tf}_{2} \mathrm{~N}\right] \mathrm{SIR}$ resin chromatographic columns saturated with metal ions at $\mathrm{pH} 3.5$ from model thin film leach solution containing (i) $\mathrm{Sn}(\mathrm{IV})$ and $\mathrm{In}(\mathrm{III})$, (ii) the glass matrix components $\mathrm{Ca}$ (II) and $\mathrm{Al}$ (III) and (iii) $\mathrm{La}(\mathrm{III}), \mathrm{Eu}(\mathrm{III}), \mathrm{Gd}(\mathrm{III})$ and Y(III) is achieved by elution with nitric acid solutions of increasing concentration. The target elements, $\mathrm{Sn}(\mathrm{IV}), \mathrm{In}(\mathrm{III})$ and the lanthanides, are readily separated from the glass matrix elements $\mathrm{Ca}(\mathrm{II})$ and $\mathrm{Al}(\mathrm{III})$ which are completely eluted from the column with $0.1 \mathrm{M} \mathrm{HNO}_{3}$, with all of the target elements being retained on the column. Effective separation of In(III) from Sn(IV) from the column can then be achieved by elution with a $2.5 \mathrm{M}$ nitric acid solution prior to recovery of $\mathrm{Sn}(\mathrm{IV})$ in stronger acid solutions. For the rare earth elements adsorbed on the DODGAA-[C $\left.\mathrm{C}_{4} \mathrm{mim}\right]\left[\mathrm{Tf}_{2} \mathrm{~N}\right] \mathrm{SIR}$ column, after $\mathrm{Ca}(\mathrm{II})$ and $\mathrm{Al}(\mathrm{III})$ removal, further separation of $\mathrm{La}(\mathrm{III})$ from the other rare earth ions present can be achieved by elution with $2.5 \mathrm{M} \mathrm{HNO}_{3}$, leaving the remaining lanthanide ions on the column to be eluted in more concentrated acid solutions.

All three SIR columns DEHPA, DODGAA and DODGAA-[C $\left.\mathrm{C}_{4} \mathrm{mim}\right]\left[\mathrm{Tf}_{2} \mathrm{~N}\right]$ can be regenerated at the end of any elution stage by rinsing with $5.0 \mathrm{M} \mathrm{HNO}_{3}$ and have been shown to be capable of re-use over a series of five cycles of loading with Y(III) stripping and rinsing, an important property in reducing reagent costs and improving the economics of using these SIRs in the recovery of critical metals from the dilute solutions obtained by leaching thin film electronic wastes.

\section{Acknowledgements}

We wish to acknowledge an EPSRC DTA Scholarship for N.S. and the EPSRC UK National Mass Spectrometry Facility at Swansea University, United Kingdom, for mass spectrometry analysis. 


\section{References}

[1] European Commission, 2014, DG Enterprise \& Industry, Brussels May 2014 Ad-hoc Working Group on Defining Critical Raw Materials, "Report on Critical Raw Materials for the EU"

[2] K.Binnemans, P.T.Jones, B.Blanpain, T.Van Gerven, Y.Yang, A.Walton, J. Clean. Prod,, 51(1), (2013), 1-22.

[3] F.Xie, T.A. Zhang, D.Dreisinger, F.Doyle, Miner. Eng., 56, (2014), 10-28

[4] C.K.Gupta, N.Krishnamurthy, Int. Mater. Rev., 37(5), (1991), 197-248

[5] Y.Li, Z.Liu, Q. Li, Q. Liu, L.Zeng, Hydrometallurgy 105(3-4), (2011), 207-212

[6] R.Bel Hadj Tahar, T.Ban, Y. Ohya, Y.Takahashi, J. Appl. Phys. 83(5), (1998), 2631-2645

[7] U.S. Geological Survey, Mineral Commodity Summaries 2016: Indium (p. 80). U.S. Department of the Interior Washington D.C. USA

[8] S.Itoh, K.Maruyama, High Temp.Mater.Proc., 30, (2011), 317-322

[9] J.Yang, T.Retegan, C.Ekberg, Hydrometallurgy, 137 (2013), 68-77

[10] S.Virolainen, D.Ibana, E Paatero Hydrometallurgy 107, (2001), 56-61

[11] L. Rocchetti, A.Amato, V.Fonti, S.Ulbaldini, I. De Michelis, B. Kopecek, F. Veglio, F. Beolchini. Waste Management, 42, (2015), 180-187

[12] P.S.Majumdar, U.S.Ray J.Indian Chem.Soc., 68, (1991), 152-153

[13] E.P.Horwitz, D.R McAlister, M.L. Dietz, Separation Sci. Technol. 41(10), (2006), 21632182

[14] N.Kabay, J.L. Cortina, A.Trochimczuk, M. Streat, React. \& Funct. Polym. 70(8), (2010), 484-496.

[15] Z.H.Wang, G.X.Ma, J.Lu, W.P.Liao, D.Q.Li, Hydrometallurgy 66(1-3), (2002), 95-99.

[16] J.S.Park, C.Han, J.Y.Lee, S.D.Kim, J.S. Kim, J.H.Wee, Sep. Purif. Technol. 43(2), (2005), $111-116$

[17] G.S.Lee, M.Uchikoshi, K.Mimura, M. Isshiki, Sep. Purif. Technol. 71(2), (2010), 186-191

[18] K.Shimojo, K.Kurahashi, H.Naganawa, Dalton Trans. 7(37), (2008), 5083-5088

[19] H.Hoshi, Y-Z.Wei, M.Kumagai, T. Asakura, Y. Morita, J. Alloy Compd. 374(1-2), (2004), 451-455

[20] S.A.Ansari, P.Pathak, P.K.Mohapatra, V.K.Manchanda, Chem. Rev. 112(3), (2012), $1751-1772$

[21] M.J.Earle, K.R.Seddon, Pure Appl. Chem. 72(7), (2000), 1391-1398.

[22] A.Stojanovic, B.K. Keppler, Sep. Purif. Technol. 47(2), (2012), 189-203

[23] A.P.Abbott, G.Frisch, J.Hartley, K.S Ryder, Green Chem. 13(1), (2011), 471-481

[24] N.Schaeffer, S.Grimes, C.Cheeseman, Inorg. Chim. Acta 439, (2016), 55-60

(25) K.Binnemans, Chem. Rev., 107(6), (2007), 2592-2614

[26]T.Vander Hoogerstraete, B.Onghena, K.Binnemans, K. J. Phys. Chem. Lett. 4(10), (2013), $1659-1663$

[27] B.Onghena, J.Jacobs, L.Van Meervelt, K. Binnemans, Dalton Trans., 43(30), (2014), 11566-11578

[28] K.Larsson, K.Binnemans, Hydrometallurgy 156, (2015), 206-214

[29] X.Sun, H.Luo, S.Dai, Talanta 90, (2012), 132-137

[30] F.Yang, F.Kubota, Y.Baba, N.Kamiya, M. Goto, J. Hazard. Mater. 254-255, (2013), 7988.

[31] X.Sun, B.Peng, Y. Ji, J. Chen, D. Li. Sep. Purif. Technol. 63(1), (2008), 61-68

[32] R.Navarro, I. Saucedo, M.A.Lira, E.Guibal, Sep. Purif. Technol. 45(12-13), (2010), 19501962

[33] R.Navarro, I. Saucedo, C. Gonzaleza, E.Guibal, Chem. Eng. J. 185-186, (2012), 226-235

[34] R.Navarro, P. Ruiz, I.Saucedo, E.Guibal, Sep. Purif. Technol. 135, (2014), 268-277

[35] H.Luo, S.Dai, P.V.Bonnesen, Anal. Chem. 76(10), (2004), 2773-2779 